\title{
Whey proteins and their antimicrobial properties in donkey milk: a brief review
}

\author{
Diana Brumini ${ }^{1}$ - Andrea Criscione ${ }^{1}$. \\ Salvatore Bordonaro $^{1}$ - Gerd Elisabeth Vegarud ${ }^{2}$. \\ Donata Marletta ${ }^{1}$
}

Received: 3 April 2015 /Revised: 1 July 2015 / Accepted: 2 July 2015 /

Published online: 23 July 2015

(C) INRA and Springer-Verlag France 2015

\begin{abstract}
Milk is a source of bioactive compounds essential for health and growth of newborns. Donkey milk, rich in lactose and whey proteins, has been proven to be a good breast milk substitute during infancy and adequate nourishment for patients with cow milk protein allergy. Beside, this milk is gaining a growing interest for human nutrition because of some other alleged health benefit. It shows antibacterial activity toward a wide range of Gram-positive and Gram-negative bacteria, stimulates immune system in convalescence, regulates gastrointestinal flora, and prevents inflammatory and autoimmune diseases. As regards its antimicrobial properties, although all the milk components might contribute to this activity, the whey protein fraction of donkey milk is generally believed to play the main role. The aim of this review is to highlight the antimicrobial properties of donkey milk with a special focus on the whey protein fraction. The effects of preservation and processing treatments on whey protein content and antimicrobial activity are also discussed.
\end{abstract}

Keywords Donkey milk $\cdot$ Whey protein $\cdot$ Antimicrobial properties $\cdot$ Processing treatment

\section{Introduction}

In the first months of life, colostrum and milk provide to the newborn a variety of compounds able to fulfil all nutritional requirements and perinatal passive immunization. In addition, milk is crucial for setting up the oral tolerance to nutrient molecules in

Donata Marletta

d.marletta@unict.it

1 Dipartimento di Agricoltura, Alimentazione e Ambiente (Di3A) Sezione di Produzioni Animali, Università degli Studi di Catania, Via Valdisavoia 5, 95123 Catania, Italy

2 Department of Chemistry, Biotechnology and Food Science (IKBM), Norwegian University of Life Sciences, P. O. Box 5003, N-1432 Ås, Norway 
the newborn, allowed through the passage of milk proteins and peptides, which, after digestion, stimulate the mucosa immune system of the infant (Baldi et al. 2005). When the mother is not able to breast feed, or after weaning, it becomes important to find an adequate alternative nourishment. Equidae milk has the most comparable protein composition to human milk among different species (Table 1); in particular, donkey milk (DM) often represents a good natural breast milk substitute during early infancy. It has a peculiar protein composition, and it is rich in polyunsaturated fatty acids, essential amino acids, and lactose (Guo et al. 2007). Donkey milk contains a low level of total protein (about 1.7\%) and a low casein/whey protein ratio (on average 1.3) with values ranging from 0.66 to 1.33 in individual milk along the lactation (Tidona et al. 2011a). This ratio is believed to play a crucial role in the sensitization to cow milk protein fraction, reducing the allergenic capacity: the lower the value, the lower the allergenic capacity (Lara-Villoslada et al. 2005). Although thorough studies would have to be conducted to achieve more conclusive results (Alessandri and Mari 2007), in vivo donkey milk showed to be well tolerated by children with cow milk protein allergy (CMPA) in terms of clinical tolerability (Restani et al. 2002; Monti et al. 2007; Swar 2011). In vitro monoclonal and polyclonal antibodies produced against cow milk proteins showed a very mild cross-reaction with donkey milk (Restani et al. 2009; El-Agamy et al. 2009).

Furthermore, donkey milk is known to possess natural protective antimicrobial factors and a specific epidermal growth factor (EGF) that suggest its beneficial impact on gastrointestinal mucosa health and integrity; a claim particularly valuable for children, the elderly, and convalescents, who have a reduced immune defense system (Scafizzari et al. 2009).

For these reasons, in recent years, donkey milk has been considered also a functional food because it contains healing properties above and beyond its basic nutritional value. The high content of lactose gives a good palatability and makes it a good growth medium for potentially probiotic strains of L. rhamnosus (Coppola et al. 2002) and exerts a good effect on gut health.

In raw donkey milk, the foodborne pathogens are generally absent and the somatic cells and total bacterial count are often low suggesting it could be a safe food, if the mammary gland is healthy and the animals are milked in proper hygienic conditions (Pilla et al. 2010). On the other hand, the high value of antimicrobial components as well as the lysozyme confers on donkey milk a long natural shelf life and bactericidal

Table 1 Milk gross composition (\%) of different species

\begin{tabular}{lcccccll}
\hline & Total solid & Protein & Fat & Lactose & Ash & $\begin{array}{l}\text { Casein/whey } \\
\text { protein ratio }\end{array}$ & Reference \\
\hline Human & 11.9 & 0.9 & 3.8 & 7.0 & 0.2 & $0.4: 1$ & Hambræus (1984) \\
Donkey & 9.4 & 1.7 & 0.4 & 6.9 & 0.4 & $1.3: 1$ & Salimei et al (2004) \\
Horse & 10.1 & 2.1 & 1.2 & 6.4 & 0.4 & $1.1: 1$ & Malacarne et al. (2002) \\
Cow & 12.6 & 3.4 & 3.7 & 4.8 & 0.7 & $4.7: 1$ & Jenness (1974) \\
Goat & 12.2 & 3.5 & 3.8 & 4.1 & 0.8 & $3.5: 1$ & Park (2006) \\
Camel & 13.3 & 3.5 & 4.0 & 4.9 & 0.9 & $3.3: 1$ & Shamsia (2009) \\
\hline
\end{tabular}


action on pathogen or potentially pathogen bacteria (Zhang et al. 2008; Nazzaro et al. 2010b).

Recently, donkey milk was shown to have positive effects on the regulation of immune response in healthy elderly consumers (Jirillo et al. 2010). In addition, its antimicrobial activity has been tested and proved effective against bacteria and viruses often associated with intestinal infection (Nazzaro et al. 2010a; Tidona et al. 2011b; Šarić et al. 2012; Brumini et al. 2013a).

The aim of this brief review is to collect the first reports on antimicrobial properties of fresh donkey milk, with a special focus on its whey proteins. The effect of some processing (heating, fermentation, digestion) on whey protein content and antimicrobial activity is also discussed.

\section{Donkey whey proteins with antimicrobial activity}

Milk has a natural protective function: it can increase resistance to infection and inhibit the action of potentially pathogenic microorganisms. Antimicrobial activity in milk is mainly attributed to some minor whey proteins: lactoferrin (Lf), lysozyme (Lyz), immunoglobulins (Igs), and lactoperoxidase (LP) (Baldi et al. 2005; Yamauchi et al. 2006); their content may vary largely between species, breeds, and individuals because of genetic or breeding variants.

The whole whey protein fraction of donkey milk is considered to be responsible for the low total bacterial count reported in literature (Chiavari et al. 2005; Šaric et al. 2012); the antimicrobial activity is mainly attributed to Lyz and, to a lesser extent, to Lf (Uniacke-Lowe et al. 2010).

Some studies suggest that Lyz, Lf, and Igs, working together in donkey milk, create synergy with potential function in the digestive tract to inhibit microbial growth and contribute to reduce the incidence of gastrointestinal infections, especially during infancy and in childhood (Baldi et al. 2005; Businco et al. 2000).

In donkey milk, particularly rich in lysozyme, a synergistic activity of Lyz with Lf and some fatty acids with known antibacterial activity as well as linoleic, lauric, and oleic acid which is the most abundant could also contribute to donkey milk's strong overall antibacterial activity against both Gram-positive and Gram-negative bacteria (Šarić et al. 2014a). In fact, the interaction of Lf with the lipopolysaccharidic (LPS) layer is reported to cause disruption of the outer membrane and enhance susceptibility of Gram-negative bacteria to the lysozyme by increasing in membrane permeability (Ellison and Giehl 1991; Farnaud and Evans 2003; Benkerroum 2008).

Whey proteins content in donkey milk is about $4.9-9.6 \mathrm{mg} \cdot \mathrm{mL}^{-1}$ (Table 2) and is mainly made up of $\beta$-lactoglobulin $(\beta$-Lg), $\alpha$-lactalbumin $(\alpha-\mathrm{La})$, lysozyme (Lyz), immunoglobulins $\left(\operatorname{Ig}_{s}\right)$, serum albumin $(\mathrm{SA})$, and lactoferrin $(\mathrm{Lf})$. Some variation of the protein composition in donkey's milk has been observed during lactation (Tidona et al. 2011a; Guo et al. 2007). In Sicilian Ragusano donkey breed, the milk showed a constant reduction of total protein content, due to the decrease of casein fraction (about $0.63 \mathrm{~g} .100 \mathrm{~g}^{-1}$ ); as a consequence, the casein/whey protein ratio ranged from 1.33 to 0.60 from early to late lactation (Tidona et al. 2011a). Within the whey protein fraction, $\beta-\mathrm{Lg}, \alpha-\mathrm{La}$, and Lyz decrease, whereas Igs increase and Lf maintains around the same amount during lactation (Guo et al. 2007; Vincenzetti et al. 2008). 
Table 2 Whey protein content in different milks/species

\begin{tabular}{lllllll}
\hline Content $\left(\mathrm{g} . \mathrm{L}^{-1}\right)$ & Human & Donkey $^{\mathrm{a}}$ & Horse & Cow & Goat & Camel $^{\mathrm{b}}$ \\
\hline Total whey protein & $6.2-8.3$ & $4.9-9.6$ & $7.4-9.1$ & $5.5-7.0$ & $3.7-7$ & $5.9-8.1$ \\
$\beta$-lactoglobulin & - & $1.3-5.5$ & 2.55 & $3.2-3.3$ & $1.5-5.0$ & - \\
$\alpha$-lactalbumin & $1.9-3.4$ & $0.8-2.7$ & 3.37 & $1.2-1.3$ & $0.7-2.3$ & $0.8-3.5$ \\
Serum albumin & $0.4-0.5$ & 0.4 & 0.37 & $0.3-0.4$ & & $7-11.9$ \\
Immunoglobulins & $0.96-1.3$ & 1.30 & 1.63 & $0.5-1.0$ & & $1.5-19.6$ \\
Lactoferrin & $1.5-2$ & $0.005-0.05$ & $0.1-2.0$ & $0.02-0.5$ & $0.02-0.2$ & $0.02-7.28$ \\
Lysozyme & $0.1-0.89$ & $0.67-4.00$ & $0.5-1.33$ & $(70-600) \times 10^{-6}$ & $250 \times 10^{-6}$ & $(60-1350) \times 10^{-6}$ \\
\hline
\end{tabular}

Data from Claeys et al. (2014)

${ }^{a}$ Data from Salimei et al. (2004); Chiavari et al. (2005); Coppola et al. (2002); Vincenzetti et al. (2008, 2010 and 2011). Gubić et al. (2014); Tidona et al. (2011a, b); Guo et al. (2007); and Šarić et al. (2014c)

${ }^{\mathrm{b}}$ Data from Shamsia (2009)

\section{$2.1 \beta$-lactoglobulin}

$\beta$-lactoglobulin ( $\beta-\mathrm{Lg}$ ) is the major whey protein except for human, camel, lagomorphs (hares, rabbits and pikas), and rodent milk (Uniacke-Lowe et al. 2010). It is a globular soluble protein with a molecular weight of about $18 \mathrm{~kg} \cdot \mathrm{mol}^{-1}$ (Farrell et al. 2004) which is believed to play several biological roles (Sawyer 2003).

In donkey milk, the $\beta$ - Lg showed a molecular weight of about $18.4 \mathrm{~kg} \cdot \mathrm{mol}^{-1}$ and a mean content of $1.3-5.5 \mathrm{mg} \cdot \mathrm{mL}^{-1}$. Recently, Gubić et al. (2014) reported a very low content of $\beta$ - $\operatorname{Lg}$ (from 139 to $263 \mathrm{mg} . \mathrm{L}^{-1}$ ) in ten Balkan donkeys together with a high level of $\alpha$-lactalbumin.

Donkey $\beta$-Lg consists of two components, the major $\beta$ - $\operatorname{Lg}$ I of 162 amino acid (aa) residues and the minor $\beta$-Lg II of 163 aa, deriving from the insertion of a Gly between the 116th and the 117th residues, as occurs in mare's milk. $\beta$-Lg I (gij125913) represents about $80 \%$ of total $\beta$-Lg and has only two variants, A and B: the former is of $18,528 \mathrm{~g} \cdot \mathrm{mol}^{-1}$, the latter is of 18,514 g.mol ${ }^{-1}$ (Godovac-Zimmermann et al. 1990). In contrast, $\beta$-Lg II (gij125904) (Mw 18,200 g.mol ${ }^{-1}$ ) that represents the remaining $20 \%$ of the $\beta-\mathrm{Lg}$ fraction has five genetic variants. The variants $\mathrm{A}, \mathrm{B}, \mathrm{C}$ (Godovac-Zimmermann et al. 1990; Herrouin et al. 2000), D (Cunsolo et al. 2007), and E (Chianese et al. 2013) showed molecular weight ranging from 18,227 (variant B) to 18,311 g. $\mathrm{mol}^{-1}$ (variant D).

$\beta-\mathrm{Lg}$, absent in human milk, is generally considered to be, together with casein fraction, one of the main causes of CMPA (Restani et al. 2009) because it is able to elicit an allergic reaction in sensitive subjects (Uniacke-Lowe et al. 2010). In this light, the identification of animals producing milk lacking in $\beta$-Lg II protein (Criscione et al. 2009) appears promising to solve potential residual cases of reactivity (Wal 2002).

Moreover, though the $\beta-\mathrm{Lg}$ is generally resistant to human gastrointestinal enzymes, probably because of the binding of fatty acids in the barrel of the structure, resistance to peptic digestion is different among species, so that ovine $\beta$-Lg is far more digestible than bovine counterpart (El-Zahar et al. 2005). Interestingly, donkey $\beta$-Lg is highly degraded $(70 \%)$ in vitro by human gastric (HGJ) and duodenal juice (HDJ) (Tidona 
et al. 2014) that is twice as much in comparison to cow counterpart (Inglistad et al. 2010). This higher degradability of donkey's $\beta$-Lg could enhance $\beta$-Lg tolerability and the yield of derived bioactive peptides in gut with potential antimicrobial activity (Tidona et al. 2011b).

In general, quantitative variation $\beta$-lactoglobulin has an effect on $\beta$-lactoglobulin digestibility; in fact, two rare samples lacking the $\beta$-lactoglobulin II showed a more rapid and complete degradation of the $\beta$-lactoglobulin fraction, particularly during the gastric digestion step (Tidona et al. 2014).

\section{$2.2 \alpha$-lactalbumin}

$\alpha$-lactalbumin $(\alpha$-La) is a globular small calcium metalloprotein, homologous with the well-characterized C-type lysozyme. Synthesized in the rough endoplasmic reticulum of the mammary gland, it is transported to the Golgi apparatus where it carries out its primary physiological function of the lactose synthesis regulation. In donkey milk, the $\alpha$-La content showed a marked increase 3 months after parturition to reach a stable value of $1.8-2.1 \mathrm{mg} \cdot \mathrm{mL}^{-1}$. A recent paper reports that $\alpha$-La is the major whey protein in Balkan donkey's milk, with a content ranging from 2.7 to 1.3 g.L $\mathrm{L}^{-1}$ from early to late lactation (Gubić et al. 2014). According to the literature, the content ranges from 0.8 to 2.7 g.L. $\mathrm{L}^{-1}$ (Table 2). Donkey $\alpha$-La contains 123 amino acid residues and has a molecular weight of 14,215 g.mol ${ }^{-1}$ (Giuffrida et al. 1992). Only one $\alpha$-La genetic variant (gij262063) with two isoforms characterized by different pIs (4.76 and 5.26, respectively) have been identified so far (Cunsolo et al. 2007; Vincenzetti et al. 2012). The high similarity between donkeys and other species $\alpha$-La suggests that the presence of the same molecular structure with four intramolecular disulfide bridges is highly likely.

Donkey $\alpha-\mathrm{La}$ is resistant to gastric and duodenal enzymes, since the $95 \%$ is undigested after a two-step in vitro test (Tidona et al. 2014), so that it reaches the gut relatively intact as already reported for raw equine, cow, and human milk (Inglistad et al. 2010). Even though it shows a striking homology, in terms of amino acid sequence, with C-lysozyme, which is a known powerful antibacterial agent (LopezExposito and Recio 2008), there is no direct evidence of antimicrobial activity of donkey $\alpha$-La and/or its derived peptides, so far.

\subsection{Immunoglobulins}

Immunoglobulins (Igs) in milk are an important defense family of proteins for the newborn naturally protecting the gut mucosa against pathogenic microorganisms. They inactivate bacteria by binding to specific sites on the bacterial surface: their role is to confer passive immunity to the newborn while its own immune system is developing (Gapper et al. 2007). Three classes of immunoglobulins are commonly found in milk: immunoglobulin $\mathrm{G}$ (IgG) - the principal immunoglobulin in equine colostrum-A (IgA) - the main form in equine milk (Uniacke-Lowe et al. 2010) - and M (IgM); $\mathrm{IgG}$ is often subdivided into two subclasses, $\operatorname{IgG}_{1}$ and $\mathrm{IgG}_{2}$ (Hurley 2003).

In humans, IgG is transferred to the fetus in utero, whereas in donkey, IgGs were supplied only after parturition by colostrum and, then, by mature milk. For this reason, 
equidae milk has a higher content of that protein fraction compared with human and bovine counterparts (Uniacke-Lowe et al. 2010).

In donkey, total IgG content increases in milk during lactation, as reported by Guo et al. (2007); Gubić et al. (2014) confirmed this trend but only after a peak observed at 100th day of lactation. In general, a high amount of Igs in colostrum and in mature milk inhibit microbial growth and contribute to the immunity of the neonate; this feature is often used as an argument for attributing health beneficial effects to a given milk type or for consuming raw milk (Claeys et al. 2014). Milk Igs surely act in natural immunepassive system; besides, about $19 \%$ of ingested bovine $\operatorname{IgG}$ and $\operatorname{IgM}$ was found to retain immunological activity in the ileum of healthy human adults (Roos et al. 1995; Möller et al. 2008), so that they are also believed to exert their antimicrobial action directly in the intestine, as well as Lf and lysozyme. In addition, a recent paper showed Igs of donkey milk were highly degradated by HGJ and HDJ, but the $33 \%$ left undigested in an in vitro simulated human digestion (Tidona et al. 2014). Further investigation is needed.

\subsection{Lactoferrin}

Donkey lactoferrin (Lf) is an 80-kg.mol ${ }^{-1}$ (Vincenzetti et al. 2012) iron-binding glycoprotein of the transferrin family (Yamauchi et al. 2006). This multifunctional protein exerts several biological activities that can be different among species. However, human Lf has a significant antimicrobial bacterial activity in vivo and in vitro (Arnold et al. 1980; Sanchez et al. 1992; de Araujo and Giugliano 2001), and bovine lactoferrin, that has been deeply investigated, is associated with antimicrobial, antifungal, antiviral, immune-modulatory, and anti-carcinogenic activity (Tomita et al. 2009 for a review). The antibacterial activity of lactoferrin against a broad range of Grampositive and Gram-negative pathogens seems to be dependent on its ability to sequester iron, producing an iron-deficient environment that limits microbial growth, and also dependent on the permeabilization of bacterial cell walls by binding to the lipopolysaccharides through its N-terminus (Valenti and Antonini 2005). The genetic polymorphism can also affect antibacterial activity. Caprine Lf was observed to exert high antibacterial activity as well (Recio and Visser 2000), also in relationship with its genetic polymorphism (Lee et al. 1997).

In general, Lf in donkey milk is higher than in ruminant milk, but much lower than in mare and in human milk (Kanyshkova et al. 2001). The average amount of lactoferrin in donkey showed a very wide range of variation (Table 2); it was $0.080 \pm$ 0.0035 and 0.0048 g.L L $^{-1}$ in Italian (Vincenzetti et al. 2012) and Balkan donkeys (Šarić et al. 2012), respectively. More recently, in Balkan donkeys, Šarić et al. (2014c) reported Lf has undetectable but also a very high value $\left(0.054\right.$ g.L $\left.\mathrm{L}^{-1}\right)$, whereas Gubić et al. (2014) reported a high concentration of Lf with a decreasing trend ranging from 0.041 to 0.006 g. $\mathrm{L}^{-1}$ from the 40th to 200 th day of lactation. These findings deserve to be further investigated.

Some experimental evidences seem to suggest that also in donkey milk, Lf and Lyz work synergistically to effectively eliminate Gram-negative bacteria (Tidona et al. 2011b; Šarić et al. 2012). In fact, Lf can bind different components in the outer bacterial membrane, thereby opening "pores" for Lyz to disrupt glycosidic linkages in the interior of the peptidoglycans (Ellison and Giehl 1991; Leitch and Willcox 1999). 
Donkey's milk Lf is quite easily digested by gastric and duodenal juice (Tidona et al. 2014). This evidence suggests that Lf can play its biologic role directly in the gut (Brock 2002) as well as through its bioactive peptides called lactoferricin (Lfcin) and lactoferrampin (Lfampin) observed in cow milk produced by commercial pepsin. In this light, it is noteworthy that bovine Lfcin has not been identified after digestion by human gastrointestinal enzymes (Furlund et al. 2013).

Tidona et al. (2011b) found that the antimicrobial activity of native and digested donkey milk against different bacteria could be due to Lf both intact protein and its peptides yielded by digestion. Recently, Brumini et al. (2013b) tested the antiviral effect of donkey milk and its whey protein on Echovirus type 5, an enterovirus which infects the human gastrointestinal tract; all the fractions (whole DM, skimmed DM, DM digested by human gastrointestinal juice, and DM whey protein fraction) showed a severe inhibition of the virus replication, with the highest antiviral effect observed for the whey protein fraction, probably because of the presence of Lf. Enzymatic digestion did not enhance the antiviral effect of donkey milk. Afterwards, it was confirmed that the main antiviral on Echovirus in DM may be attributed to high molecular mass whey proteins (Lf, LP, and Igs), even if a synergic action of the diverse proteins in the whey cannot be excluded (Brumini et al. 2013b).

\subsection{Lysozyme}

Lysozyme (Lyz) acts as a natural preservative, conferring a lengthy shelf life to raw donkey's milk (Zhang et al. 2008; Šarić et al. 2012).

It is a powerful antibacterial protein (Lopez-Exposito et al. 2008) with an important role in the intestinal immune response. Lyz splits the bond between $N$ acetylglucosamine and $\mathrm{N}$-acetylmuramic acid of the peptidoglycan leading to fragments with high and low molecular weight, which are the agents responsible for the specific immune cell activations. Because of this mechanism of action, Gram-negative bacteria are less sensible to Lyz than Gram-positive. As a consequence, antibacterial action against some Gram-negative bacteria can be explained by a synergistic action of Lyz with Lf, according to Ellison and Giehl (1991).

Donkey milk lysozyme, as well as equine and canine counterpart, belongs to C-type calcium-binding lysozyme and is able to bind calcium ions; this binding leads to more stable complex with an enhanced antimicrobial activity (Wilhelm 2009). Recently, Šrić et al. (2014b) report that donkey milk shows a calcium-dependent activity against E. coli.

In donkey milk, two variants of Lyz (A and B), both containing 129 amino acids (gij126613; gij126614), and with molecular weight 14,632 g.mol ${ }^{-1}$ that differ in three amino acid substitutions at positions 48, 52, and 61 have been described so far (Herrouin et al. 2000; Cunsolo et al. 2007). Lysozyme is present with high value in donkey milk, ranging from 0.67 to 3.74 g. $\mathrm{L}^{-1}$ in Italian and Domestic Balkan donkey (Vincenzetti et al. 2011; Šarić et al. 2012; Šarić et al. 2014c), and maintains the same high percentage (13.13-15.44) over the total protein during 150 days of lactation (Guo et al. 2007). In contrast, a decreasing trend was described in Balkan donkeys with values of 2.9 and 1.7 g.L $\mathrm{L}^{-1}$ from 40 to 200 days of lactation (Gubić et al. 2014).

Donkeys' milk showed a significant antibacterial activity against Listeria monocytogenes and Staphylococcus aureus (Šarić et al. 2014a) that was also put in 
relationship with the high content of Lyz that ranged from 0.67 to 3.54 g.L $\mathrm{L}^{-1}$ together with good amount of some fatty acids, namely linoleic, lauric, and oleic acid, with wellknown antibacterial activity toward Gram-positive bacteria (Galbraith et al. 1971; Galbraith and Miller 1973).

Donkey milk's Lyz is resistant to digestion: only the $25 \%$ of the total protein is digested in vitro by gastrointestinal juice (Tidona et al. 2014). It is also thermostable even after a thermal treatment of $63^{\circ} \mathrm{C}$ for $30 \mathrm{~min}$ (Coppola et al. 2002; Di Cagno et al. 2004; Chiavari et al. 2005).

\subsection{Lactoperoxidase}

Lactoperoxidase (LP) is an oxidoreductase enzyme with protective function against microorganism infections. The enzyme contains a heme group, carbohydrates (about $10 \%$ ), and a calcium ion. LP is a major antibacterial agent in bovine colostrum (de Wit and van Hooydonk 1996). The amount of lactoperoxidase in donkey milk has been scarcely investigated. According to Vincenzetti et al. (2012), it was $0.11 \pm$ $0.027 \mathrm{mg} \cdot \mathrm{mL}^{-1}$, closer to human milk $\left(0.77 \mathrm{mg} \cdot \mathrm{mL}^{-1}\right)$ (Shin et al. 2001) than bovine milk $\left(0.03 \pm 0.1 \mathrm{mg} \cdot \mathrm{mL}^{-1}\right)$ (Janet and Tanaka 2007).

Beghelli et al. (2011), testing antioxidant properties of donkey milk, detected a lactoperoxidase activity equivalent to about $0.11 \mathrm{mg} \cdot \mathrm{mL}^{-1}$. A very low peroxidase activity $\left(4.83 \pm 0.35 ; 1.39 \pm 0.23 ; 2.88 \pm 0.51 \mathrm{mU} . \mathrm{mL}^{-1}\right)$ was found in fresh, frozen, and powered donkey milk, respectively (Mariani 2010). The low activity confirms the small concentration of LP in fresh donkey milk.

In contrast, this enzyme could be of significant nutritional interest in raw fresh milk and, since it works in synergy with Lf and Lyz, could contribute to enhance the natural preservative action of donkey milk and may function in the infant's digestive tract to reduce the incidence of gastrointestinal infections (Businco et al. 2000). In fact, the total antibacterial effect in milk is greater than the sum of the individual contributions of immunoglobulin and non-immunoglobulin defense proteins. This is thought to be for their synergy or for the presence of natural bactericidal peptide (Clare and Swaisgood 2000).

\section{Influence of different processing treatments on whey protein content and antimicrobial activity of donkey milk}

Fresh raw donkey milk is gaining an increasing popularity as "healthy food." When produced under standard conditions, donkey milk shows a low total bacterial count (about $4 \times 10^{4}$ CFU.mL ${ }^{-1}$ ) (Coppola et al. 2002) and keeps a low value even during about 4 days of storage (Chiavari et al. 2005; Šarić et al. 2012). The high content of Lyz and other non-specific antimicrobial compounds gives to raw fresh donkey milk a long natural shelf life and makes a prolonged heat treatment unnecessary, which is normally required for preserving hygienic quality and nutritional properties. However, it still needs thermal treatments in order to guarantee its healthiness and quality over time.

The most common method of sanitization is the pasteurization at $63{ }^{\circ} \mathrm{C}$, which generally is not expected to affect the main nutritional and health properties (Coppola et al. 2002; Chiavari et al. 2005). Other preservation methods, such as drying (spray- 
drying and freeze-drying) or fermentation, allow a longer storage but can significantly affect milk protein composition and their functional properties.

Polidori and Vincenzetti (2010) evaluated the effect on the whey fraction of donkey milk of two technological processes, freezing and spray-drying, as a two-step process which includes a strong thermal treatment to produce powdered milk. Total whey protein and lysozyme contents were almost similar in fresh $\left(7.5\right.$ and $\left.1 \mathrm{mg} \cdot \mathrm{mL}^{-1}\right)$, frozen $\left(7.2\right.$ and $\left.1 \mathrm{mg} \cdot \mathrm{mL}^{-1}\right)$, and spray-dried/powdered $\left(6.7\right.$ and $0.94 \mathrm{mg} \cdot \mathrm{mL}^{-1}$ ) donkey milk. Lysozyme activity remained the same in fresh and frozen donkey milk $\left(\mathrm{U} \cdot \mathrm{mL}^{-1}=0.035\right)$ also after 1 month of storage at $4{ }^{\circ} \mathrm{C}$, in the case of fresh donkey milk. In contrast, powdered donkey milk retained only the $30 \%$ of the lysozyme activity; thermal denaturation started at $70{ }^{\circ} \mathrm{C}$.

Lyophilisation, or freeze-drying, is another powdering process obtained by low temperature and vacuum. Fresh and freeze-dried donkey milk show a similar protein composition in terms of caseins and total proteins, except for $\alpha-\mathrm{La}$; on the contrary, a significant reduction of these fractions can be observed in frozen milk after 1 and 2 months of storage (Vincenzetti et al. 2011). In the same experimental conditions, Lyz maintained its high level and enzymatic activity.

The fermentation process increases the good lactic acid bacteria (LAB) in milk and at the same time reduces the content of pathogen bacteria. As a consequence, fermented milk enhances gut health preventing and/or reducing the most common infections supported by bacteria and viruses. A general concern on donkey milk is that the high level of Lyz inhibits the growth of some lactobacilli or can cause a severe selection on several LAB strains. On the other hand, fresh donkey milk is a rich natural resource of probiotic bacteria which are capable to colonize the colon, acting directly in the gut against outcome pathogen bacteria and also stimulating the immune system (Nazzaro et al. 2012). Recently, eight bacterial strains belonging to Lactobacillus genus have been isolated from donkey milk; they might be used in fermented milk or yogurt (Nazzaro et al. 2012). Besides, if fermented, donkey milk will yield metabolites such as acetate and lactate that inhibit the growth of potential enteropathogens (Fooks and Gibson 2002) and others with several healthy functions including antibacterial activity (Nazzaro et al. 2008). Lactic acid present at the end of the fermentation could also decrease the $\mathrm{pH}$ value in the intestine acting as bacteria antagonist and facilitate calcium absorption (Lan et al. 2007). The synergism among natural compound of milk, microorganisms, and metabolites positively influences the intestinal flora composition and the defense system mechanisms of the host (Fooks and Gibson 2002).

Finally, two different probiotic strains, added in donkey milk before lyophilization, maintained their viability after milk reconstitution, suggesting the possibility of producing a probiotic infant formula with beneficial properties using donkey's milk as raw material (Vincenzetti et al. 2011).

The digestion process, as well as fermentation, is able to breakdown the proteins to shorter peptide chains. Besides native proteins, the biological action could be exerted by bioactive peptides; endowed sequences, inactive while part of the protein, that after the passage through the stomach and intestine, are partially or totally hydrolyzed into fragments (Hill et al. 2000; Yalcin 2006).

In a recent study, donkey milk revealed to be a good source of antimicrobial bioactive peptides, released during in vitro simulated gastrointestinal digestion processes, able to inhibit the replication of three enterobacteria (Tidona et al. 2011b). $\beta$-Lg 
and $\mathrm{Lf}$ are the highest digested fractions, while $\alpha$-La and Lyz are the most resistant proteins; however, since part of those proteins remain undigested, continuing to perform their action intact (Tidona et al. 2011b), the antimicrobial activity might result from a synergism of the intact proteins and peptides.

Nazzaro et al. (2010a) digested donkey milk with commercial pepsin in order to identify additional components, other than lysozyme, with antimicrobial activity on pathogenic microorganisms. Some chromatographic fractions, obtained from hydrolyzed milk proteins, contained bio-molecules with antimicrobial effect on different bacteria and with a strain-dependent activity within the same species.

\section{Conclusions and future perspective}

In the light of these first findings, the antimicrobial properties of donkey milk whey proteins against bacteria, both Gram positive and Gram negative, and viruses (Table 3) seem very promising. In many case, the role of the single whey protein (Lf, Lyz, LP, Igs) as well as its mechanism of action remain to be fully clarified. Nonetheless, these arguments reinforce the claim of donkey milk as functional food with diverse bioactivities. It surely represents a valuable natural breast milk substitute, useful both to strengthen the host's immune defense systems and to preserve gut health in infancy.

Table 3 Antimicrobial activity of donkey milk against/toward different microorganisms

\begin{tabular}{|c|c|c|}
\hline Microorganism & Type of Sample & Reference \\
\hline Bacillus cereus DSM4384 & Hydrolyzed donkey milk & Nazzaro et al. $2010 \mathrm{a}$ \\
\hline Bacillus cereus RT INF01 & Digested donkey Milk & Tidona et al. 2011a, b \\
\hline Echovirus type $5^{\mathrm{a}}$ & $\begin{array}{l}\text { Whey proteins of donkey } \\
\text { milk }\end{array}$ & Brumini et al. 2013a, b \\
\hline Enterococcus faecalis DSM2352 & Hydrolyzed donkey milk & Nazzaro et al. 2010a \\
\hline Escherichia coli ATCC 10536 & Donkey milk & $\begin{array}{l}\text { Šarić et al. 2012; Šarić et al. } \\
\text { 2014b }\end{array}$ \\
\hline Escherichia coli ATCC 8739 & Donkey milk & Šarić et al. 2014b \\
\hline Escherichia coli (EPEC) 10208355 & Digested donkey Milk & Tidona et al. 2011a, b \\
\hline Listeria monocytogenes ATCC 19111 & Donkey milk & Šarić et al. $2014 \mathrm{a}$ \\
\hline Listeria monocytogenes 2230/92 & Digested donkey Milk & Tidona et al. 2011a, b \\
\hline $\begin{array}{l}\text { Salmonella choleraesuis (CGMCC } \\
\text { 1.1859) }\end{array}$ & Donkey milk & Zhang et al. 2008 \\
\hline Salmonella enteritidis ATCC 13076 & Donkey milk & Šarić et al. 2012; Šarić et al. 2014c \\
\hline Salmonella livingstone & Donkey milk & Šarić et al. 2014c \\
\hline Salmonella typhimurium ATCC 14028 & Donkey milk & Šarić et al. 2014c \\
\hline Shigella dysenteriae (CGMCC 1.1869) & Donkey milk & Zhang et al. 2008 \\
\hline Staphylococcus aureus ATCC 25923 & Donkey milk & Šarić et al. 2014a \\
\hline Staphylococcus aureus DSM25923 & Hydrolyzed donkey milk & Nazzaro et al. $2010 \mathrm{a}$ \\
\hline
\end{tabular}

${ }^{\text {a }}$ Virus 
Furthermore, natural antimicrobial activity of donkey milk can strengthen host defense, stimulates the immune system, regulates gastrointestinal flora, and prevents inflammatory and autoimmune diseases in children and adults.

Therefore, a wider consumption of fresh donkey milk could be definitely advisable not only for babies or for patients affected by CMPA but also for different categories of consumers, including the elderly and convalescents, with reduced immune defense system. Nevertheless, despite the recent expansion of specialized donkey breeding, donkey milk is still a "niche product," which often can only be retailed in farms for direct consumption. Fermented milk can represent a good alternative, suggested by some authors. Moreover, the application of some new technologies, such as lyophilisation and, to a lesser extent, microencapsulation could enable a better exploitation of this product. However, various factors have to be taken into account such as the stability, the biological activity, and the cost.

Further studies are needed to identify the components with higher antimicrobial properties and to evaluate other bioactivities, both in vitro and in vivo, in order to promote the potential use of donkey milk as functional food or as bioactive compound to formulate functional foods and drinks. Genomics and proteomics could provide cutting edge approaches in this topic.

In conclusion, considering its nutritional profile, it would be worth to deepen the study of donkey milk components in order to exploit those features and, at the same time, safeguard donkey breeds. In fact, promoting a wider consumption of fresh, powdered, and fermented donkey milk might entail a revitalization in the breeding of donkeys, a species at serious risk of extinction.

\section{References}

Alessandri C, Mari A (2007) Efficacy of donkey's milk in treating cow's milk allergic children: major concerns (Letter to the Editor). Pediatr Allergy Immunol 18:625-626

Arnold RR, Brewer M, Gauthier JJ (1980) Bactericidal activity of human lactoferrin: sensitivity of a variety of microorganisms. Infect Immun 28:893-898

Baldi A, Politis I, Pecorini C, Fusi E, Chronopoulou R, Dell'Orto V (2005) Biological effects of milk proteins and their peptides with emphasis on those related to the gastrointestinal eco system. J Dairy Res 72:66-72

Beghelli D, Vincenzetti S, Micozzi D, Vita V, Polidori P (2011) Antioxidant properties of donkey milk. 19th Congress of Animal Science and Production Association. Ital J Anim Sci 10(s1):48

Benkerroum N (2008) Antimicrobial activity of lysozyme with special relevance to milk. Afr J Biotechnol 7: 4856-4867

Brock JH (2002) The physiology of lactoferrin. Biochem Cell Biol 80:1-6

Brumini D, Bø Furlund C, Comi I, Devold TG, Marletta D, Vegarud GE, Monceyron Jonassen C (2013a) Antiviral activity of donkey milk protein fractions on echovirus type 5. Int Dairy J 28:109-111

Brumini D, Bø Furlund C, Tidona F, Devold TG, Marletta D, Vegarud GE, Monceyron Jonassen C (2013b) Antiviral activity of donkey milk on echovirus type 5: a preliminary study-Attività antivirale del latte di asina su echovirus tipo 5: uno studio preliminare. Sci Tecn Latt Cas 64(5-6):155-158

Businco L, Giampietro PG, Lucenti P (2000) Allergenicity of mare's milk in children with cow's milk allergy. J Allergy Clin Immunol 105:1031-1034

Chianese L, De Simone C, Ferranti P, Mauriello R, Costanzo A, Quarto M, Garro G, Picariello G, Mamone G, Ramunno L (2013) Occurrence of qualitative and quantitative polymorphism at donkey betalactoglobulin II locus. Food Res Int 54:1273-1279

Chiavari C, Coloretti F, Nanni M, Sorrentino E, Grazia L (2005) Use of donkey's milk for a fermented beverage with lactobacilli. Lait 85:481-490 
Claeys W, Verraes C, Cardoen S, De Block J, Huyghebaert A, Raes K, Dewettinck K, Herman L (2014) Consumption of raw or heated milk from different species: an evaluation of the nutritional and potential health benefits. Food Control. doi:10.1016/j.foodcont.2014.01.045

Clare DA, Swaisgood HE (2000) Bioactive milk peptides: a prospectus. J Dairy Sci 83:1187-1195

Coppola R, Salimei E, Succi M, Sorrentino E, Nanni M, Ranieri P, Belli Blanes R, Grazia L (2002) Behaviour of Lactobacillus rhamnosus strains in ass's milk. Ann Microbiol 52:55-60

Criscione A, Cunsolo V, Bordonaro S, Guastella AM, Saletti R, Zuccaro A, D’Urso G, Marletta D (2009) Donkeys' milk protein fraction investigated by electrophoretic methods and mass spectrometric analysis. Int Dairy J 19:190-197

Cunsolo V, Costa A, Saletti R, Muccilli V, Foti S (2007) Detection and sequence determination of a new variant beta-lactoglobulin II from donkey. Rapid Commun Mass Spectrom 21:1438-1446

de Araujo AN, Giugliano LG (2001) Lactoferrin and free secretory component of human milk inhibit the adhesion of enteropathogenic Escherichia coli to HeLa cells. BMC Microbiol 1:25. doi:10.1186/14712180-1-25

de Wit JN, van Hooydonk ACM (1996) Structure, functions and applications of lactoperoxidase in natural antimicrobial systems. Neth Milk Dairy J 50:227-244

Di Cagno R, Tamborrino A, Gallo G, Leone C, De Angelis M, Faccia M (2004) Uses of mares' milk in manufacture of fermented milk. Int Dairy J 14:767-775

El-Agamy EI, Nawar M, Shamsia SM, Awad S, Haenlein GFW (2009) Are camel milk proteins convenient to the nutrition of cow milk allergy children? Small Rumin Res 82:1-6

Ellison RT 3rd, Giehl TJ (1991) Killing of gram-negative bacteria by lactoferrin and lysozyme. J Clin Invest 88:1080-1091

El-Zahar K, Sitohy M, Choiset Y, Métro F, Haertlé T, Chobert JM (2005) Peptic hydrolysis of ovine $\beta$ lactoglobulin and $\alpha$-lactalbumin. Exceptional susceptibility of native ovine $\beta$-lactoglobulin to pepsinolysis. Int Dairy J 15:17-27

Farnaud S, Evans RW (2003) Lactoferrin - a multifunctional protein with antimicrobial properties. Mol Immunol 40:395-404

Farrell HM, Jimenez-Flores R, Bleck GT, Brown EM, Butler JE, Creamer LK, Hicks CL, Hollar CM, NgKwai-Hang KF, Swaisgood HE (2004) Nomenclature of the proteins of cows' milk - sixth revision. J Dairy Sci 87:1641-1674

Fooks LJ, Gibson GR (2002) Probiotics as modulators of the gut flora. Br J Nutr 88:S39-S49

Furlund CB, Ulleberg EK, Devold TG, Flengsrud R, Jacobsen M, Sekse C, Holm H, Vegarud GE (2013) Identification of lactoferrin peptides generated by digestion with human gastrointestinal enzymes. J Dairy Sci $96: 75-88$

Galbraith H, Miller TB (1973) Effect of long chain fatty acids on bacterial respiration and amino acid uptake. J Appl Bacteriol 36:659-675

Galbraith H, Miller TB, Paton AM, Thompson JK (1971) Antibacterial activity of long chain fatty acids and the reversal with calcium, magnesium, ergocalciferol and cholesterol. J Appl Microbiol 34:803-813

Gapper LW, Copestake DEJ, Otter D, Indyk HE (2007) Analysis of bovine immunoglobulin G in milk, colostrum and dietary supplements: a review. Anal Bioanal Chem 389:93-109

Giuffrida MG, Cantisani A, Napolitano L, Conti A, Godovac-Zimmermann J (1992) Biol Chem Hoppe Seyler 373:931

Godovac-Zimmermann J, Conti A, Sheil M, Napolitano L (1990) Covalent structure of the minor monomeric beta-lactoglobulin II component from donkey milk. Biol Chem Hoppe Seyler 371:871

Gubić J, Tasić T, Tomić J, Torbica A (2014) Determination of whey proteins profile in Balkan donkey's milk during lactation period. J Hyg Engin Des 8:178-180

Guo HY, Pang K, Zhang XY, Zhao L, Chen SW, Dong ML (2007) Composition, physiochemical properties, nitrogen fraction distribution, and amino acid profile of donkey milk. J Dairy Sci 90:1635-1643

Hambræus L (1984) Human milk composition. Nutr Abstr Rev Clin Nutr Ser A 54:219-236

Herrouin M, Mollè D, Fauquant J, Ballestra F, Maubois JL, Lèonil J (2000) New genetic variants identified in Donkey's milk whey proteins. J Protein Chem 19:105-115

Hill HS, Doull F, Rutherford KJ, Cross ML (2000) Immunoregulatory peptides in bovine milk. Br J Nutr 84: S111-S117

Hurley WL (2003) Immunoglobulins in mammary secretions. In: Fox PF, McSweeney PLK (eds) Advanced dairy chemistry: proteins, vol 1, 3rd edn. Kluwer Academic/Plenum Publishers, New York

Inglistad RA, Devold TG, Eriksen EK, Holm H, Jacobsen M, Liland KH (2010) Comparison of the digestion of caseins and whey proteins in equine, bovine, caprine and human milks by human gastrointestinal enzymes. Dairy Sci Technol 90:549-563 
Janet RL, Tanaka T (2007) Antimicrobial activity of lactoferrin and lactoperoxidase in milk. In: Janet RL (ed) Dietary Protein Research Trends, Nova Science Publisher Inc. New York pp. 101-115

Jenness R (1974) The composition of milk. In: Larson BL, Smith VR (eds) Lactation: a comprehensive treatise, vol III. Academic, New York

Jirillo F, Jirillo E, Magrone T (2010) Donkey's and Goat's milk consumption and benefits to human health with special reference to the inflammatory status. Curr Pharm Des 16:859-863

Kanyshkova TG, Buneva VN, Nevinsky GA (2001) Lactoferrin and its biological functions. Biochem Mosc 66:1-7

Lan A, Lagadic-Gossmann D, Lemaire C, Brenner C, Jan G (2007) Acidic extracellular pH shifts colorectal cancer cell death from apoptosis to necrosis upon exposure to propionate and acetate, major end-products of the human probiotic propionibacteria. Apoptosis 12:573-591

Lara-Villoslada F, Olivares M, Xaus J (2005) The balance between caseins and whey proteins in cow's milk determines its allergenicity. J Dairy Sci 88(5):1654-1660

Lee TH, Yu SL, Nam MS, Kim SJ, Lee KK, Yu DY, Shimazaki K (1997) Polymorphic sequence of Korean native goat lactoferrin exhibiting greater antibacterial activity. Anim Genet 28(5):367-369

Leitch EC, Willcox MD (1999) Elucidation of the antistaphylococcal action of lactoferrin and lysozyme. J Med Microbiol 48:867-871

Lopez-Exposito I, Recio I (2008) Protective effect of milk peptides: antibacterial and antitumor properties. In: Bosze Z (ed) Advances in experimental medicine and biology: bioactive components of milk. Springer, New York

Lopez-Exposito I, Pellegrini A, Amigo L, Recio I (2008) Synergistic effect between different milk-derived peptides and proteins. J Dairy Sci 91:2184-2189

Malacarne M, Martuzzi F, Summer A, Mariani P (2002) Protein and fat composition of mare's milk: some nutritional remarks with reference to human and cow's milk. Int Dairy J 12:869-877

Mariani P (2010) Donkey milk nutraceutical characteristics: a biochemical evaluation of nutritious and clinical properties. PhD thesis, Doctoral course in Ageing and Nutrition (XXII cycle) - University of Camerino (MC) -Italy. Available at: http://cameprints.unicam.it/284 Accessed 1st Apr 2015

Möller NP, Scholz-Ahrens KE, Roos N, Schrezenmeir J (2008) Bioactive peptides and proteins from foods: indication for health effects. Eur J Nutr 47:171-182

Monti G, Bertino E, Muratore MC, Coscia A, Cresi F, Silvestro L, Fabris C, Fortunato D, Giuffrida MG, Conti A (2007) Efficacy of donkey's milk in treating highly problematic cow's milk allergic children: an in vivo and in vitro study. Pediatr Allergy Immunol 18:258-264

Nazzaro F, Anastasio M, Fratianni F, Orlando P (2008) Isolation and identification of prebiotic lactic acid bacteria from raw donkey milk. Int J Prob Preb 3:374

Nazzaro F, Orlando P, Fratianni F, Coppola R (2010a) Isolation of components with antimicrobial property from the donkey milk: a preliminary study. Open Food Sci J 4:43-47

Nazzaro F, Fratianni F, Orlando P, Coppola R (2010b) The use of probiotic strains in the production of a donkey milk-based functional beverage. Int J Prob Preb 2:91-96

Nazzaro F, Orlando P, Conti A (2012) Probiotic microorganism isolated from donkey milk. United States Patent Application Publication. Pub. No.: US 2012/0128821 A1

Park YW (2006) In: Park YW, Haenlein GFW (eds) Handbook of milk of non-bovine mammals. Goat milkchemistry and nutrition. Blackwell Publishers, Ames, pp 34-58

Pilla R, Daprà V, Zecconi A, Piccinini R (2010) Hygienic and health characteristics of donkey milk during a follow-up study. J Dairy Res 77:392-397

Polidori P, Vincenzetti S (2010) Differences of protein fractions among fresh, frozen and powdered donkey milk. Recent Pat Food Nutr Agric 2:56-60

Recio I, Visser S (2000) Antibacterial and binding characteristics of bovine, ovine and caprine lactoferrins: a comparative study. Int Dairy J 10:597-605

Restani P, Beretta B, Fiocchi A, Ballabio C, Galli C (2002) Cross-reactivity between mammalian proteins. Ann Allergy Asthma Immunol 89:11-15

Restani P, Ballabio C, Di Lorenzo C (2009) Molecular aspects of milk allergens and their role in clinical events. Anal Bioanal Chem 395:47-56

Roos N, Mahe S, Benamouzig R, Sick H, Rautureau J, Tome D (1995) 15N-labeled immunoglobulins from bovine colostrum are partially resistant to digestion in human intestine. J Nutr 125:1238-1244

Salimei E, Fantuz F, Coppola R, Chiofalo B, Polidori P, Varisco G (2004) Composition and characteristics of ass's milk. Anim Res 53:67-78

Sanchez L, Calvo M, Brock JH (1992) Biological role of lactoferrin. Arch Dis Child 67:657-661

Šarić L, Šarić BM, Mandić AI, Torbica AM, Tomić JM, Cvetković DD, Okanović DG (2012) Antibacterial properties of domestic Balkan donkeys' milk. Int Dairy J 25:142-146 
Šarić LC, Šarić BM, Kravić ST, Plavšić DV, Milovanović IL, Gubić JM, Nedeljković NM (2014a) Antibacterial activity of domestic Balkan donkey milk toward Listeria monocytogenes and staphylococcus aureus. Food Feed Res 4:47-54

Šarić LC, Šarić BM, Mandić AI, Kevrešan ZS, Ikonić BB, Kravić SZ, Jambrec DJ (2014b) Role of calcium content in antibacterial activity of donkeys' milk toward E. coli. Eur Food Res Technol 239:1031-1039

Šarić L, Šarić B, Mandić A, Tomić J, Torbica A, Nedeljković N, Ikonić B (2014c) Antibacterial activity of donkey milk against Salmonella. Agro Food Ind Hi Tech 25:30-34

Sawyer L (2003) $\beta$-Lactoglobulin. In: Fox PF, McSweeney PLH (eds) Advanced dairy chemistry. Proteins, vol 1, 3rd edn. Kluwer Academic/Plenum Publishers, New York, pp 319-386

Scafizzari M, Giannico F, Potere O, Trani A, Colonna MA, Zezza L, Vonghia G, Caputi Jambreghi A (2009) Epidermal growth factor (EGF) in mare and ass milk: a preliminary investigation. Ital J Anim Sci 8(Suppl 2):737

Shamsia SM (2009) Nutritional and therapeutic properties of camel and human milks. Int J Genet Mol Biol 1: $52-58$

Shin K, Hayasawa H, Lönnerdal B (2001) Purification and quantification of lactoperoxidase in human milk with use of immunoadsorbents with antibodies against recombinant human lactoperoxidase. Am J Clin Nutr 73:984-989

Swar MO (2011) Donkey milk-based formula: a substitute for patients with cow's milk protein allergy. Sudan J Paediatr 11:21-24

Tidona F, Criscione A, Guastella AM, Bordonaro S, Marletta D (2011a) Gross composition and nutritional properties of donkey milk produced in Sicily. Composizione chimica e proprietà nutrizionali del latte di asina prodotto in Sicilia. Sci Tecn Latt Cas 62:217-221

Tidona F, Sekse C, Criscione A, Jacobsen M, Bordonaro S, Marletta D, Vegarud GE (2011b) Antimicrobial effect of donkeys' milk digested in vitro with human gastrointestinal enzymes. Int Dairy J 21:158-165

Tidona F, Criscione A, Devold TG, Bordonaro S, Marletta D, Vegarud GE (2014) Protein composition and micelle size of donkey milk with different protein patterns: effects on digestibility. Int Dairy J 35:57-62

Tomita M, Wakabayashi H, Shin K, Yamauchi K, Yaeshima T, Iwatsuki K (2009) Twenty-five years of research on bovine lactoferrin applications. Biochimie 91:52-57

Uniacke-Lowe T, Huppertz T, Fox PF (2010) Equine milk proteins: chemistry, structure and nutritional significance. Int Dairy J 20:609-629

Valenti P, Antonini G (2005) Lactoferrin: an important host defence against microbial and viral attack. Cell Mol Life Sci 62:2576-2587

Vincenzetti S, Polidori P, Mariani P, Cammertoni N, Fantuz F, Vita A (2008) Donkey's milk protein fractions characterization. Food Chem 106:640-649

Vincenzetti S, Savini M, Cecchini C, Micozzi D, Carpi F, Vita A, Polidori P (2011) Effects of lyophilization and use of probiotics on donkey's milk nutritional characteristics. Int J Food Eng. doi:10.2202/1556-3758. 2032

Vincenzetti S, Amici A, Pucciarelli S, Vita A, Micozzi D, Carpi FM, Polzonetti V, Natalini P, Polidori P (2012) A proteomic study on donkey milk. Biochem Anal Biochem 1:109. doi:10.4172/2161-1009.1000109

Wal JM (2002) Cow's milk proteins/allergens. Ann Allergy Asthma Immunol 89:3-10

Wilhelm KR (2009) Protein complexes: assembly, structure and function. http://umu.diva-portal.org/smash/ get/diva2:278077/FULLTEXT02 Accessed 22.05.2015

Yalcin AS (2006) Emerging therapeutic potential of whey proteins and peptides. Curr Pharm Des 12:16371643

Yamauchi K, Wakabayashi H, Shin K, Takase M (2006) Bovine lactoferrin: benefits and mechanism of action against infections. Biochem Cell Biol 84(3):291-296

Zhang X, Zhao L, Jiang L, Dong M, Ren F (2008) The antimicrobial activity of donkey milk and its microflora changes during storage. Food Control 19:1191-1195 